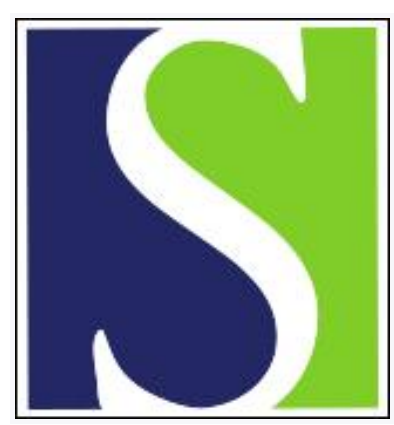

Scand J Work Environ Health 1993;19(5):334-341

https://doi.org/10.5271/sjweh.1466

Issue date: 01 Oct 1993

Urinary mercury excretion in chloralkali workers after the cessation of exposure.

by Ellingsen DG, Thomassen Y, Langard S, Kjuus $\mathrm{H}$

Affiliation: Department of Occupational Medicine, Telemark Central Hospital, Porsgrunn, Norway.

This article in PubMed: www.ncbi.nlm.nih.gov/pubmed/8296182

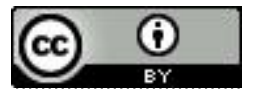




\title{
Urinary mercury excretion in chloralkali workers after the cessation of exposure
}

\author{
by Dag G Ellingsen, MD, ${ }^{1}$ Yngvar Thomassen, MSc, ${ }^{2}$ Sverre Langård, MD, ${ }^{1}$ Helge Kjuus, $\mathrm{MD}^{1}$
}

\begin{abstract}
ELLINGSEN DG, THOMASSEN Y, LANGÅRD S, KJUUS H. Urinary mercury excretion in chloralkali workers after the cessation of exposure. Scand J Work Environ Health 1993;19:334 41. Seventeen former chloralkali workers were followed through the regular determination of urinary mercury for nearly two years after the cessation of exposure to mercury vapor in a study of the time course of urinary mercury elimination. Their duration of exposure ranged from $3 \mathrm{~d}$ to 35.5 years. A one-compartment model for urinary mercury elimination was applied. The urinary mercury concentration declined at a rate indicating a half-time of $91 \mathrm{~d}$. When corrected for an individual base-line level of urinary mercury resulting from sources of mercury intake not related to work, the half-time was 72.4 [95\% confidence interval $(95 \% \mathrm{CI}) 63.2-81.7$ ] d, with a mean elimination rate constant of 0.011 $(95 \%$ CI $0.008-0.013) \cdot \mathrm{d}^{-1}$. The day-to-day variability of the urinary mercury concentration averaged $22 \%$, expressed as the coefficient of variation between urine samples delivered on three consecutive days.
\end{abstract}

Key terms: chloralkali workers, half-time, mercury vapor, urinary excretion kinetics.

There are limited data on the time course of urinary mercury elimination in humans after exposure to mercury vapor. In an experimental study (1), five volunteers were followed for $7 \mathrm{~d}$ after being exposed to radiolabeled mercury vapor for 14 to $24 \mathrm{~min}$. The mean elimination half-time for mercury in the kidney region was calculated to be $64 \mathrm{~d}$. An initial marginal increase in the urinary mercury concentration after the cessation of exposure was demonstrated among the same volunteers (2). In a three-week follow-up of six workers with long-term exposure to mercury vapor, a fast initial decrease was observed in the urinary mercury concentration with a half-time of approximately $2 \mathrm{~d}$, followed by a slow excretion phase with an elimination rate constant of $0.01 \cdot \mathrm{d}^{-1}$ (3). In a study on nine men exposed to mercury vapor for $20-45 \mathrm{~h}$, an increase in urinary mercury concentration was observed for the first $19 \mathrm{~d}$ after exposure, followed by an average urinary mercury elimination half-time of $50 \mathrm{~d}$. The time of followup was 4-37 months (4). Roels et al (5) observed seven workers for about $250-300 \mathrm{~d}$ after the cessation of mercury vapor exposure. Their application of a one-compartment elimination model yielded a mean urinary mercury half-time of $90 \mathrm{~d}$.

The present investigation is part of a study on adverse effects among former chloralkali workers previously exposed to mercury vapor $(6,7)$. Its aim was

1 Department of Occupational Medicine, Telemark Central Hospital, Porsgrunn, Norway.

2 National Institute of Occupational Health, Oslo, Norway.

Reprint requests to: Dr DG Ellingsen, Department of Occupational Medicine, Telemark Central Hospital, N-3906 Porsgrunn, Norway. to study the time course of urinary mercury elimination in a postexposure period of two years among former chloralkali workers exposed to mercury vapor and, furthermore, to estimate the elimination halftime and the elimination rate constant.

\section{Subjects and methods}

\section{Subjects and exposure}

The study group was recruited from workers at a chloralkali plant which was closed in 1987 and subsequently dismantled. Subjects who had ceased being exposed between 1987 and 1989 were asked to participate in the study. Sixteen men and one woman volunteered to deliver urine samples for the determination of urinary mercury for a period of two years after the cessation of their mercury vapor exposure. Four of the subjects had been involved in the dismantling of the plant, and 13 had participated in regular production, nine as maintenance or mechanical repair workers and four as cell room operators.

All of the participants were in good health, and seven had participated in a comprehensive clinical examination in another part of the present project $(6$, 7). The subjects averaged 38.1 (range 18.7-58.9) years of age when the exposure ceased. The average duration of exposure was 6.2 years (range 3 days35.5 years). Ten subjects had been exposed for more than one year. The characteristics of the subjects are presented in table 1 .

A cumulative urinary mercury "dose" was calculated for each individual on the basis of the urinary mercury concentrations determined during their time of exposure. This dose surrogate was constructed by summing the mean urinary mercury concentration excreted each year. Further details regarding the es- 
tablishment of this "dose" have been presented elsewhere (6).

One subject stopped participating $280 \mathrm{~d}$ after the cessation of exposure. Two subjects delivered their last urine samples between 500 and 600 d postexposure, while the remaining subjects were monitored for more than $700 \mathrm{~d}$. The mean time of follow-up was from day 11 (range $1-30$ ) to day 702 (range 280 812) postexposure.

\section{Sampling procedure}

All of the subjects were instructed to deliver a first void morning urine sample, a procedure which had been practiced at the plant since 1948 when biological monitoring of urinary mercury commenced. Urinary mercury was determined by routine analyses at the laboratory of the study plant (laboratory A) up to 1988 . From that time on a noncompany laboratory (laboratory B) performed the analyses. However, for about four months in 1988, the analyses were carried out in duplicate in both laboratories. Whenever possible, the urine samples were collected on three consecutive days from March 1988 on so that we could account for the day-to-day variability in the urinary mercury excretion,. The samples were collected and stored in separate $\mathrm{NUNC}^{\circledR}$ polyethylene tubes.

In all, 376 single urine specimens were collected from the 17 subjects. The results of the determined mercury concentrations in the samples from consecutive days were averaged after analysis for the purpose of data presentation. Thus 217 individual results of urinary mercury were used to assess the time course of urinary mercury excretion, 53 from laboratory $A$ and 164 from laboratory $B$. Urinary mercury was determined in 72 samples in both laboratories. In the cases for which the urinary mercury concentration was determined in both laboratories, the concentrations determined in laboratory $\mathrm{B}$ were used in the study of urinary mercury elimination. Otherwise these results were used to assess the interlaboratory differences in the measured urinary mercury concentrations. All of the samples were determined from fresh urine over the entire period of monitoring.

\section{Determination of urinary mercury}

Laboratory A had measured mercury in urine since 1948. Up to 1975 this laboratory applied spectrophotometric detection of mercury after acid mineralization (dithizone method). In 1975 cold vapor atomic absorption spectrophotometry was introduced and subsequently used through 1987 . A modified potassium permanganate/sulfuric acid $\left(\mathrm{KMnO}_{4} / \mathrm{H}_{2} \mathrm{SO}_{4}\right)$ digestion and stannous tin $\left(\mathrm{Sn}^{++}\right)$reduction procedure (8) and a laboratory data control mercury spectrophotometer (model 1235) was used. In the absence of quality assurance materials, both laboratories (A and B) had regularly determined mercury in the same urine specimens, selected randomly since the $1950 \mathrm{~s}$ until the plant was closed. Laboratory A generally reported somewhat higher values (about 10\%) than laboratory B. This difference can be explained by loss of mercury during the two- to three-week storage period before measurements in laboratory $\mathrm{B}$.

Urinary mercury was determined by laboratory B using a cold vapor batch generation system coupled with a laboratory data control mercury spectrophotometer (model 1235). Two replicates of $125 \mu \mathrm{l}$ from the preheated urine specimens $\left(85^{\circ} \mathrm{C}\right.$, to redissolve urine precipitates) were injected into a stannic chloride/sodium hydroxide $\left(\mathrm{SnCl}_{4} / \mathrm{NaOH}\right)$ reservoir and analyzed for mercury. The detection limit of the method is $2 \mathrm{nmol} \cdot \mathrm{l}^{-1}$. The accuracy and precision of the mercury measurements were monitored with human quality control material (Seronorm Trace Element 108, Nycomed Ltd, Oslo, Norway). The within-day and between-day variations of this material typically had a relative standard deviation of $1 \%$. The average mercury concentration measured in this material ( $245 \mathrm{nmol} \cdot \mathrm{l}^{-1}, \mathrm{~N}=15, \mathrm{SD}=2$ ) was in agreement with the recommended value of $250 \mathrm{nmol}^{-\mathrm{l}^{-1}}$. The urinary mercury concentrations were corrected for urinary dilution by correcting for urinary creatinine, which was determined by a Beckman creatinine analyzer 2 (9).

\section{Statistics}

A one-compartment model was assumed after the individual time courses of the urinary mercury elimination were studied. The fast first phase of urinary mercury excretion reported by Piotrowski et al (3) was not observed in the individual elimination curves in our study, nor was the rise in the postexposure urinary mercury concentration which has been reported by Barregård et al (4).

The results of the urinary mercury measurements were log-transformed. After about one year of fol-

Table 1. Some characteristics of the 17 previously mercury exposed subjects.

\begin{tabular}{|c|c|c|c|c|}
\hline & $\begin{array}{c}\text { Age at } \\
\text { exposure } \\
\text { cessation } \\
\text { (years) }\end{array}$ & $\begin{array}{l}\text { Duration of } \\
\text { exposure }\end{array}$ & $\begin{array}{c}\text { Cumulative } \\
\text { urinary } \\
\text { mercury } \\
\left(\left.\mathrm{nmol} \cdot\right|^{-1}\right)\end{array}$ & $\begin{array}{l}\text { Total } \\
\text { time of } \\
\text { follow-up } \\
\text { (d) }\end{array}$ \\
\hline $\begin{array}{l}A^{a} \\
B \\
C \\
D \\
E \\
F \\
G \\
H \\
I \\
J \\
K \\
L \\
M \\
N \\
O \\
P \\
Q\end{array}$ & $\begin{array}{l}58.9 \\
58.7 \\
54.1 \\
24.1 \\
26.7 \\
27.8 \\
40.3 \\
18.7 \\
36.4 \\
30.2 \\
48.9 \\
32.5 \\
48.4 \\
33.0 \\
24.2 \\
55.1 \\
38.5\end{array}$ & $\begin{array}{c}14.1 \text { years } \\
1.5 \text { years } \\
35.5 \text { years } \\
6.2 \text { years } \\
9 \text { days } \\
5.8 \text { years } \\
5.0 \text { months } \\
14 \text { days } \\
5.3 \text { years } \\
11.3 \text { years } \\
7.5 \text { years } \\
10.3 \text { months } \\
7.5 \text { months } \\
11.5 \text { years } \\
2.5 \text { months } \\
3 \text { days } \\
5.3 \text { years }\end{array}$ & $\begin{array}{c}4417 \\
329 \\
11547 \\
765 \\
16^{\circ} \\
1714 \\
75 \\
10^{\circ} \\
1979 \\
4121 \\
4895 \\
90 \\
50 \\
2664 \\
36 \\
10^{\circ} \\
1534\end{array}$ & $\begin{array}{l}728 \\
592 \\
760 \\
783 \\
739 \\
726 \\
759 \\
544 \\
770 \\
706 \\
746 \\
280 \\
720 \\
812 \\
792 \\
733 \\
741\end{array}$ \\
\hline
\end{tabular}

Female.

- Estimated. 
low-up the urinary mercury concentration was low and at a level that could be expected in the general population. Hence a cutoff for follow-up was used that was chosen to correspond to the last measured individual urinary mercury concentration above 2.5 $\mathrm{nmol} \cdot \mathrm{mmol}^{-1}$ creatinine. That concentration corresponds to the mean plus two standard deviations (1.3 $+1.2 \mathrm{nmol} \cdot \mathrm{mmol}^{-1}$ creatinine) established for an occupationally unexposed reference population in the main study on clinical effects among workers previously exposed to mercury vapor (7).

In an alternative approach for correcting for the urinary mercury base-line level, attributable to sources of mercury exposure not related to work, the lowest individually recorded urinary mercury concentration was subtracted from the measured concentrations.

\section{Results}

The urinary mercury concentrations determined in both laboratory $\mathrm{A}$ and laboratory $\mathrm{B}$ were log-transformed, and a least square regression analysis was performed. The Pearson's correlation coefficient between these concentrations was $0.90(P=0.001)$. The concentrations determined in laboratory $\mathrm{A}$ averaged $96.1 \%$ of those determined in laboratory B [95\% confidence interval (95\% CI) 88.2-103.1].

Figure 1 presents the decline of urinary mercury in relation to time since cessation of exposure for two of the subjects under study (subject E and I), both monitored for more than $700 \mathrm{~d}$.

Figure 2 presents the time course of urinary mercury elimination among all of the subjects under study, the urinary mercury concentrations $(\log )$ being uncorrected for the base-line urinary mercury concentration. Data regarding these regression lines are presented in table 2 . The mean value of the correlation coefficients (Pearson) was 0.93 (range $0.80-$
1.0). A linear pattern was also apparent among the subjects with lower correlation coefficients. The mean time of follow-up was shown to be 254 (range $114-406) \mathrm{d}$ when the cutoff of $2.5 \mathrm{nmol} \cdot \mathrm{mmol}^{-1}$ creatinine was applied. According to the calculated regression lines, the urinary mercury decreased with a half-time of 91.0 (range $33.0-127.5,95 \%$ CI 79.6-102.5) d.

Figure 3 shows the median concentrations and ranges related to the time since the individual cutoffs. The bar indicating cutoff shows the last urinary mercury concentrations used in the regression analysis for each participant. Each bar represents the specified time interval since cutoff. It appears that the urinary mercury concentration declined until the time interval of $200-299 \mathrm{~d}$ after the cutoff. Because of the low urinary mercury concentrations measured after the applied cutoff value, no individual halftimes were calculated.

An unexposed reference group $(\mathrm{N}=51)$ was studied with regard to dental status in another part of the present project (7). Figure 4 shows the regression line between the surface of dental amalgam expressed as amalgam points and the urinary mercury concentrations among the referents in that study. The lowest urinary mercury concentrations determined among the nine subjects in the present study with known amalgam points are plotted in the figure (broken line). Most of the subjects had urinary mercury concentrations within the expected range when related to the amalgam points.

The urinary mercury half-time was recalculated with the concentrations measured in laboratory $\mathrm{A}$ ( $96.1 \%$ of the concentrations in laboratory B) standardized to those determined in laboratory B. Only minor changes occurred in the regression equations. Generally the correlation coefficients became somewhat higher, and the mean urinary mercury half-time was calculated to be 89.8 (range $30.8-124.4$ ) d.
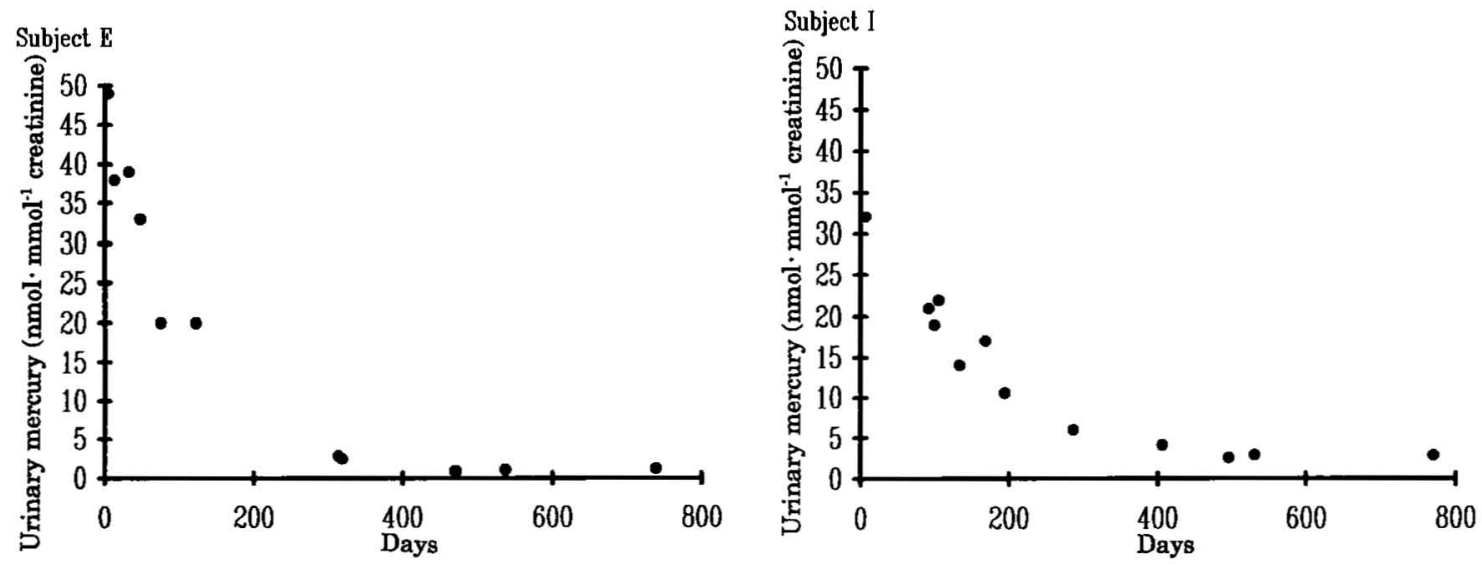

Figure 1. Time course of urinary mercury excretion in subjects $E$ and $\mathrm{I}$, followed for 739 and $770 \mathrm{~d}$, respectively. 

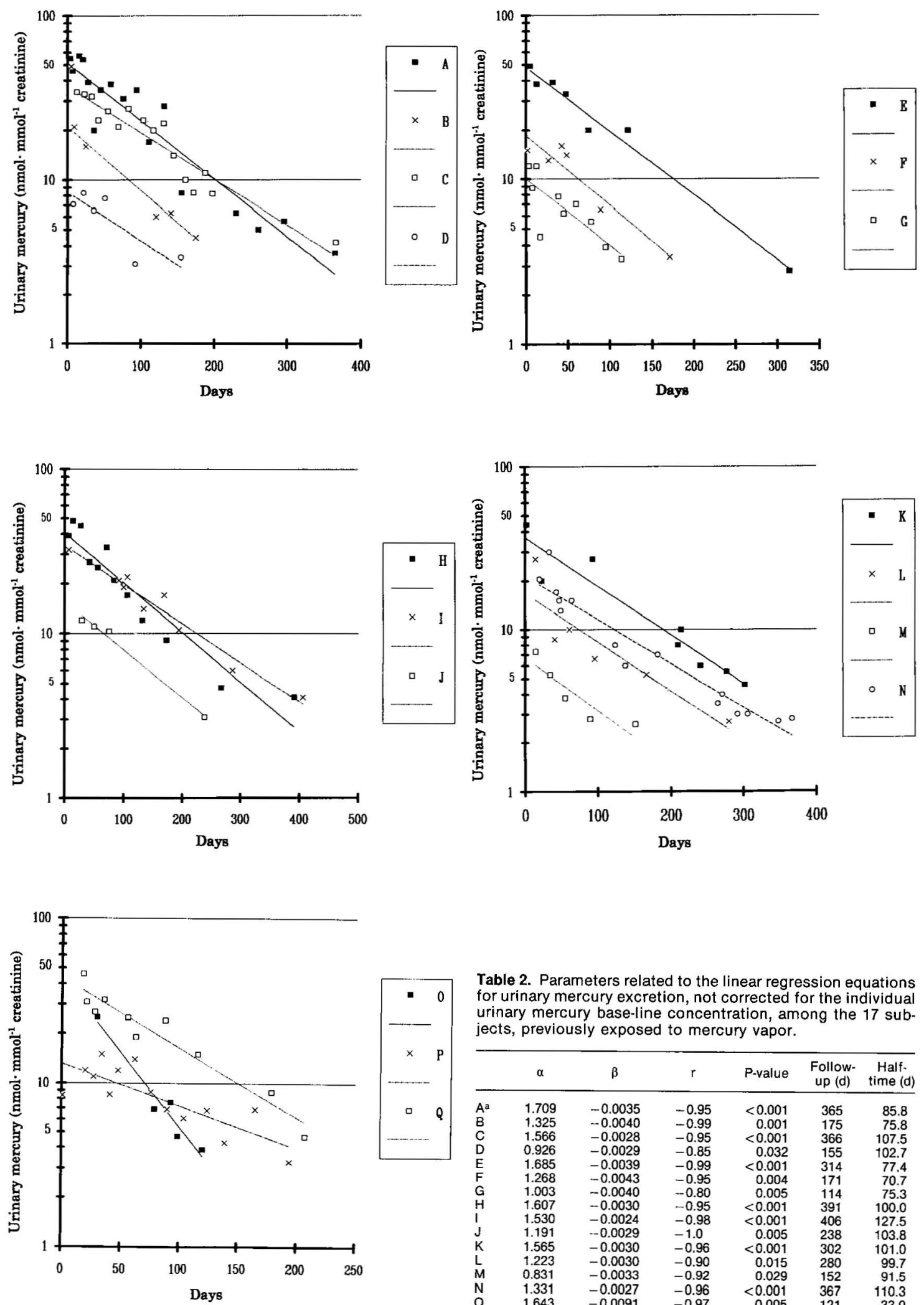

Table 2. Parameters related to the linear regression equations for urinary mercury excretion, not corrected for the individual urinary mercury base-line concentration, among the $17 \mathrm{sub}$ jects, previously exposed to mercury vapor.

\begin{tabular}{lcccrrr}
\hline & $\alpha$ & $\beta$ & $r$ & P-value & $\begin{array}{c}\text { Follow- } \\
\text { up (d) }\end{array}$ & $\begin{array}{r}\text { Half- } \\
\text { time (d) }\end{array}$ \\
\hline $\mathrm{A}^{\mathrm{a}}$ & 1.709 & -0.0035 & -0.95 & $<0.001$ & 365 & 85.8 \\
$\mathrm{~B}$ & 1.325 & -0.0040 & -0.99 & 0.001 & 175 & 75.8 \\
$\mathrm{C}$ & 1.566 & -0.0028 & -0.95 & $<0.001$ & 366 & 107.5 \\
$\mathrm{D}$ & 0.926 & -0.0029 & -0.85 & 0.032 & 155 & 102.7 \\
$\mathrm{E}$ & 1.685 & -0.0039 & -0.99 & $<0.001$ & 314 & 77.4 \\
$\mathrm{~F}$ & 1.268 & -0.0043 & -0.95 & 0.004 & 171 & 70.7 \\
$\mathrm{G}$ & 1.003 & -0.0040 & -0.80 & 0.005 & 114 & 75.3 \\
$\mathrm{H}$ & 1.607 & -0.0030 & -0.95 & $<0.001$ & 391 & 100.0 \\
$\mathrm{I}$ & 1.530 & -0.0024 & -0.98 & $<0.001$ & 406 & 127.5 \\
$\mathrm{~J}$ & 1.191 & -0.0029 & -1.0 & 0.005 & 238 & 103.8 \\
$\mathrm{~K}$ & 1.565 & -0.0030 & -0.96 & $<0.001$ & 302 & 101.0 \\
$\mathrm{~L}$ & 1.223 & -0.0030 & -0.90 & 0.015 & 280 & 99.7 \\
$\mathrm{M}$ & 0.831 & -0.0033 & -0.92 & 0.029 & 152 & 91.5 \\
$\mathrm{~N}$ & 1.331 & -0.0027 & -0.96 & $<0.001$ & 367 & 110.3 \\
$\mathrm{O}$ & 1.643 & -0.0091 & -0.97 & 0.005 & 121 & 33.0 \\
$\mathrm{P}$ & 1.123 & -0.0026 & -0.81 & $<0.001$ & 194 & 114.9 \\
$\mathrm{Q}$ & 1.639 & -0.0043 & -0.96 & $<0.001$ & 207 & 70.8 \\
\hline
\end{tabular}

Figure 2. Time course of urinary mercury excretion among all of the study subjects, the urinary mercury concentrations being uncorrected for the base-line level.

a Female. 


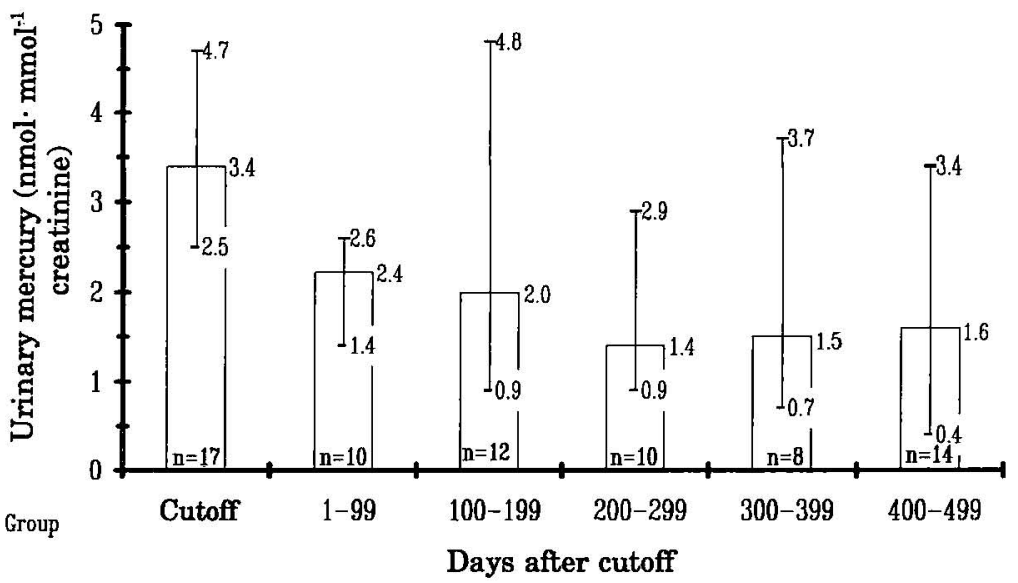

Figure 3. Median urinary mercury concentrations measured after a cutoff of $2.5 \mathrm{nmol} \cdot \mathrm{mmol}^{-1} \mathrm{creatinine}$. Each bar represents the median concentration among the subjects $(n)$ who delivered urine samples in the specified range of time.

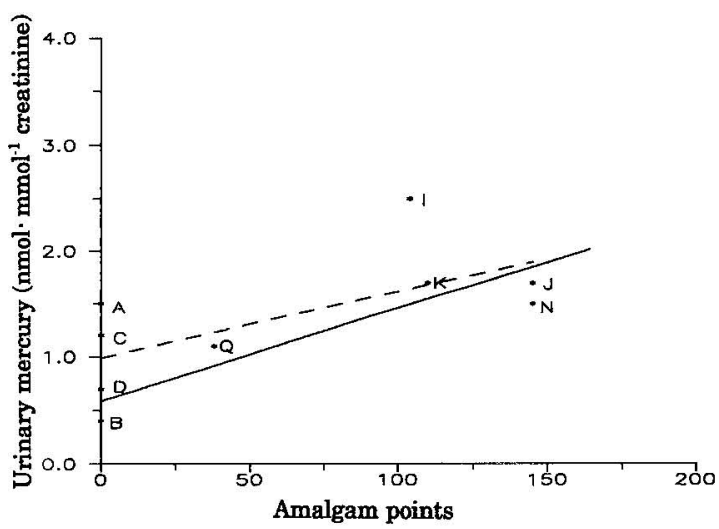

Figure 4. Urinary mercury concentrations related to the surface of dental amalgam among 51 unexposed subjects (drawn line) and the lowest urinary mercury concentrations among nine subjects with known amalgam status in the present study, plotted into the figure (broken line).

The surface of dental amalgam has been shown to correlate with urinary mercury concentrations among subjects unexposed to mercury at work $(10,11)$. Thus dental amalgam and other sources of inorganic mercury exposure can result in an elevated "base-line level" of urinary mercury among subjects unexposed at work. The lowest measured urinary mercury concentration in each individual during the time of monitoring in the present study was used as an estimate of the base-line level. These concentrations were subtracted from the measured concentrations, and the half-time of the urinary mercury elimination was recalculated. Table 3 presents some of the parameters related to the regression equations for each individual, the recalculated half-times, and the elimination rate constants $\left(k \cdot d^{-1}\right)$. One subject (subject $L$ ) was followed for less than $300 \mathrm{~d}$. His base-line level was set at $1.4 \mathrm{nmol} \cdot \mathrm{mmol}^{-1}$ creatinine, which was the mean base-line level used for correction among the remaining 16 subjects. This procedure yielded substantially lower half-times for the mean urinary mercury concentration, which was 72.4 (range 27.895.6, 95\% CI 63.2-81.7) d. The elimination rate constant averaged 0.011 (range $0.007-0.025,95 \%$ CI $0.008-0$. 013) $\cdot \mathrm{d}^{-1}$. Figure 5 shows the time course for urinary mercury elimination among subjects $A$ to $D$ with the use of both values corrected and values uncorrected for the urinary mercury baseline level.

No significant association was observed between the calculated half-times and the cumulative urinary mercury dose or the number of months exposed. When the subjects were dichotomized according to the duration of exposure (cut point 12 months), the half-time of the urinary mercury decline among the subjects exposed for more than 12 months $(\mathrm{N}=10)$ did not differ significantly from the half-time of the subjects exposed for less than 12 months $(\mathrm{N}=7)$.

Seventy-five urinary mercury concentrations in the present study were based on urine samples delivered for analysis from three consecutive days. Laboratory $B$ determined these samples. These concentrations were mainly observed at the end of the follow-up. The mean mercury concentration was 2.8 (range 0.4-20.0) $\mathrm{nmol} \cdot \mathrm{mmol}^{-1}$ creatinine. The coefficient of variation was calculated for each series of three analyses, and the mean coefficient of variation was 22 (range $4-64) \%$.

\section{Discussion}

In our study urinary mercury was determined in fresh urine. Both participating laboratories took part in in- 
Table 3. Parameters related to the linear regression equations for urinary mercury excretion among the 17 subjects previously exposed to mercury vapor. Estimations made after correction for individual base-line urinary mercury concentrations.

\begin{tabular}{|c|c|c|c|c|c|c|c|}
\hline & $\alpha$ & $\beta$ & $r$ & P-value & $\begin{array}{l}\text { Follow-up } \\
\text { (d) }\end{array}$ & $\begin{array}{l}\text { Half-time } \\
\text { (d) }\end{array}$ & $\begin{array}{l}\text { Elimination } \\
\text { constant } \\
\text { (k/d) }\end{array}$ \\
\hline $\begin{array}{l}A^{a} \\
B \\
C \\
D \\
E \\
F \\
G \\
H \\
I \\
J \\
K \\
L^{b} \\
M \\
N \\
O \\
P \\
Q\end{array}$ & $\begin{array}{l}1.716 \\
1.317 \\
1.568 \\
0.892 \\
1.695 \\
1.294 \\
0.948 \\
1.618 \\
1.568 \\
1.189 \\
1.560 \\
1.215 \\
0.783 \\
1.334 \\
1.729 \\
1.089 \\
1.641\end{array}$ & $\begin{array}{l}-0.0041 \\
-0.0041 \\
-0.0032 \\
-0.0034 \\
-0.0044 \\
-0.0080 \\
-0.0052 \\
-0.0040 \\
-0.0033 \\
-0.0043 \\
-0.0035 \\
-0.0040 \\
-0.0039 \\
-0.0037 \\
-0.0108 \\
-0.0034 \\
-0.0047\end{array}$ & $\begin{array}{l}-0.95 \\
-0.99 \\
-0.95 \\
-0.85 \\
-0.99 \\
-0.96 \\
-0.81 \\
-0.97 \\
-0.98 \\
-0.99 \\
-0.96 \\
-0.94 \\
-0.91 \\
-0.98 \\
-0.98 \\
-0.81 \\
-0.96\end{array}$ & $\begin{array}{r}<0.001 \\
0.001 \\
<0.001 \\
0.032 \\
<0.001 \\
0.002 \\
0.005 \\
<0.001 \\
<0.001 \\
0.008 \\
<0.001 \\
0.006 \\
0.031 \\
<0.001 \\
<0.001 \\
<0.001 \\
<0.001\end{array}$ & $\begin{array}{l}365 \\
175 \\
366 \\
155 \\
314 \\
171 \\
114 \\
391 \\
406 \\
238 \\
302 \\
280 \\
152 \\
367 \\
121 \\
194 \\
207\end{array}$ & $\begin{array}{l}74.0 \\
72.7 \\
95.6 \\
87.8 \\
68.3 \\
37.5 \\
58.2 \\
76.0 \\
90.1 \\
69.7 \\
85.5 \\
74.5 \\
78.0 \\
81.8 \\
27.8 \\
89.3 \\
64.3\end{array}$ & $\begin{array}{l}-0.009 \\
-0.010 \\
-0.007 \\
-0.008 \\
-0.010 \\
-0.019 \\
-0.012 \\
-0.009 \\
-0.008 \\
-0.010 \\
-0.008 \\
-0.009 \\
-0.009 \\
-0.009 \\
-0.025 \\
-0.008 \\
-0.011\end{array}$ \\
\hline
\end{tabular}

a Female.

Base line estimated.
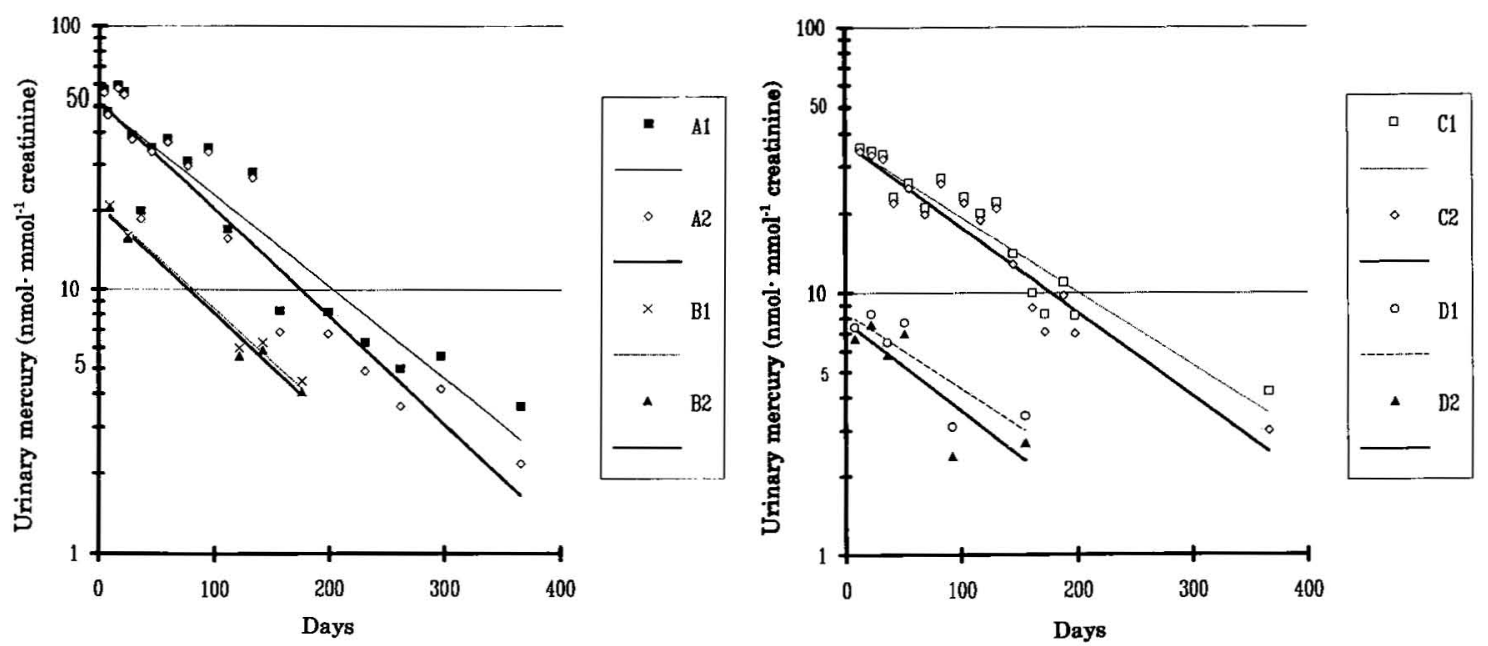

Figure 5. Time course of urinary mercury excretion with levels uncorrected (A1-D1) and corrected (A2-D2) for the baseline urinary mercury concentrations among subjects $A$ to $D$.

ternal quality control linked to external interlaboratory control. Therefore, it is likely that the results are accurate. The results from the analyses in the laboratories were in agreement.

Various studies have shown a substantial diurnal variation in urinary mercury excretion $(12,13)$. To reduce this variability, we analyzed the mercury concentrations in morning urine samples and corrected for urinary dilution. In addition, we collected samples from three consecutive days whenever possible and averaged the measured concentrations. The variation coefficient of the mercury concentrations measured in the urine specimens from consecutive days was $22 \%$, a value indicating a substantial dayto-day variation in mercury excretion.

The participants were followed from day 11 postexposure on the average. Some studies have presented conflicting results regarding the first phase of urinary excretion after the cessation of mercury exposure. Piotrowski et al (3) observed a fast washout phase in the first days of postexposure with an elimination half-time of $2 \mathrm{~d}$ in three chloralkali workers exposed to mercury vapor. During $7 \mathrm{~d}$ of postexposure Cherian et al (2) observed a low correlation between urinary mercury and the duration of follow-up for five volunteers exposed to mercu- 
ry vapor from 14 to $24 \mathrm{~min}$. Barregård et al (4) observed an increase in urinary mercury excretion which reached a plateau at $19 \mathrm{~d}$ postexposure. The results in the present study were too sparse to permit an assessment of the excretion during the first days of postexposure.

The participants were monitored for about $700 \mathrm{~d}$ on the average. During this time the concentration of urinary mercury reached a level considered to be in the "normal range." To avoid estimation of halftimes that were too long, a cutoff value for the urinary mercury concentration above the "normal range" had to be determined.

Urinary mercury concentration also reflects exposure to inorganic mercury from sources not related to work (ie, dental amalgam). Elimination half-times which are too long can be calculated if one does not correct for this base-line level. The individual baseline level chosen for correction in the present study was, on the average, $1.4 \mathrm{nmol} \cdot \mathrm{mmol}^{-1}$ creatinine, which is in agreement with the mean urinary mercury concentration of $1.3 \mathrm{nmol} \cdot \mathrm{mmol}^{-1}$ creatinine in the previously mentioned study (7) among subjects with exposure not related to work.

The correlation coefficients calculated between the number of days of postexposure and the urinary mercury concentrations were high in most instances (median Pearson's correlation coefficient 0.95), and they were only below 0.90 for three subjects.

In our study the concentration of urinary mercury decreased with a half-time of 72.4 and $91.0 \mathrm{~d}$ for corrected and uncorrected urinary mercury concentrations, respectively.

On the assumption that correction for a base-line level is appropriate, our results indicate $72.4(95 \%$ CI 63.2-81.7) $\mathrm{d}$ as the best estimate of the half-time of urinary mercury elimination and a corresponding urinary elimination rate constant of $0.011(95 \% \mathrm{Cl}$ $0.008-0.013) \cdot \mathrm{d}^{-1}$. Hursh et al (1) reported an average half-time of $64 \mathrm{~d}$ for the kidney region by using radiolabeled mercury in volunteers followed for $7 \mathrm{~d}$. On the assumption that urinary mercury concentration is an index of the renal mercury burden, as suggested by Cherian et al (2), our results agree with those results. Barregård et al (4) reported an average half-time of $50 \mathrm{~d}$ for urinary mercury in nine subjects after an average of $19 \mathrm{~d}$ postexposure. The use of a common half-time for all of the subjects in that study yielded an estimate of $59 \mathrm{~d}$.

Correction for a urinary base-line level was not reported by Roels et al (5) for seven chloralkali workers monitored for about $300 \mathrm{~d}$. They reported a mean urinary mercury half-time of $90 \mathrm{~d}$. Skare \& Engqvist (14) calculated a median half-time of $41 \mathrm{~d}$ in a study among dentists, assuming a one-compartment model with only two data points for each individual. The concentrations of urinary mercury in that study were low. Piotrowski et al (3) reported an elimination rate constant for the slow phase of urinary mercury excretion of $0.01 \cdot \mathrm{d}^{-1}$ among six subjects monitored for three weeks; this value is close to our estimate $\left(\mathrm{k}=0.011 \cdot \mathrm{d}^{-1}\right)$.

We monitored 14 subjects for more than $700 \mathrm{~d}$. Their median urinary mercury level was 1.6 $\mathrm{nmol} \cdot \mathrm{mmol}^{-1}$ creatinine versus $1.2 \mathrm{nmol} \cdot \mathrm{mmol}^{-1}$ creatinine in the reference group previously referred to (7). The amalgam status was known for nine of our subjects. A comparison of these subjects with the referents showed that their urinary mercury concentrations were slightly higher than expected in relation to the amalgam points. However, no calculations for half-times in a possible long-term compartment were performed due to the low urinary mercury concentrations measured at the end of the follow-up. According to the group results, the level of urinary mercury did not appear to decline for more than $200-299 \mathrm{~d}$ after the cutoff level was reached.

\section{Acknowledgments}

The authors thank Ms H Schistad for her follow-up of the subjects over a period of three years; without her help the study could not have been performed. We also thank Ms P Flor for her linguistic help.

The study was carried out with financial support from Norsk Hydro A/S, Norway.

\section{References}

1. Hursh JB, Clarkson TW, Cherian MG, Vostal JJ, Mallie RV. Clearance of mercury (Hg-197, $\mathrm{Hg}-203$ ) vapor inhaled by human subjects. Arch Environ Health 1976;31:302-9.

2. Cherian MG, Hursh JB, Clarkson TW, Allen J. Radioactive mercury distribution in biological fluids and excretion in human subjects after inhalation of mercury vapor. Arch Environ Health 1978;33:109-14.

3. Piotrowski JK, Trojanowska B, Mogilnicka EM. Excretion kinetics and variability of urinary mercury in workers exposed to mercury vapor. Int Arch Occup Environ Health 1975;35:245-56.

4. Barregård L, Sällsten G, Schütz A, Attewell R, Skerfving S, Järvholm B. Kinetics of mercury in blood and urine after brief occupational exposure. Arch Environ Health 1992;47:176-84.

5. Roels HA, Boeckx M, Ceulemans E, Lauwerys RR. Urinary excretion of mercury after occupational exposure to mercury vapor and influence of the chelating agent meso-2,3-dimercaptosuccinic acid (DMSA). Br J Ind Med 1991;48:247-53.

6. Ellingsen DG, Mørland T, Andersen A, Kjuus H. Relation between exposure related indices and neurological and neurophysiological effects in workers previously exposed to mercury vapor. Br J Ind Med. 1993; 50:736-44.

7. Ellingsen DG, Holland RI, Thomassen Y, Olstad ML, Frech W, Kjuus H. Mercury and selenium in workers previously exposed to mercury vapor at a chloralkali plant. Br J Ind Med. 1993;50:745-52.

8. Lindberg $G$. A rapid method for the determination of mercury in urine. Analyst 1970;95:264-71.

9. Flores $O$, McLean $M$. The evaluation of a new rate system for the determination of creatinine. Clin Chem 1977;23:1172.

10. Olstad ML, Holland RI, Wandel L, Hensten Pettersen A. Correlation between amalgam restorations and mer- 
cury concentrations in urine. J Dent Res 1987;66: $1179-82$.

11. Langworth S, Elinder CG, Göthe CJ, Vesterberg O. Biological monitoring of environmental and occupational exposure to mercury. Int Arch Environ Health 1991;63:161-7.

12. Barber TE, Wallis G. Correction of urinary mercury concentration by specific gravity, osmolality, and creatinine. J Occup Med 1986;28:354-9.
13. Wallis G, Barber TE. Variability in urinary mercury excretion. J Occup Med 1982;24(8):590-5.

14. Skare I, Engqvist A. Urinary mercury clearance of dental personnel after a longterm intermission in occupational exposure. Swed Dent J 1990;14:255—9.

Received for publication: 15 december 1992 